\title{
A new megaspore genus from the Lower Carboniferous (Asbian) of northern England
}

\author{
EDWIN SPINNER \\ Department of Geology, University of Sheffield, Mappin Street, Sheffield, S1 3JD, England
}

\begin{abstract}
A new megaspore genus Triangupapillaesporites is described from Lower Carboniferous deposits of northern England. The genus is characterised by a three layered exine wall, the innermost layer bearing ? papillae.
\end{abstract}

\section{INTRODUCTION}

In 1973, Neves et al. published the results of a major study in the use of miospores in the correlation of Lower Carboniferous deposits of Scotland and northern England. As part of this study a short borehole was drilled at Dodgesontown Ford, 10 miles north of Brampton, Carlisle, Cumberland.

The borehole penetrated to a depth of 65 feet, passing from a thin limestone at the surface into a series of grey siltstones and shales containing fragments of plant macrofossils and coaly streaks. Miospore preparations yield specimens typical of the Perotrilites tesselatus - Schulzospora campyloptera miospore concurrent range zone (TC zone of Neves et al. op.cit.) (personal communication Dr. K.J. Gueinn).

More recently, parts of the core have been prepared for megaspore analysis using recognised standard techniques of hydrofluoric acid, Schulze's solution and dilute potassium hydroxide solution. Preliminary study of the residues obtained has revealed a form of small megaspore which is considered to be unusual and significantly different in its morphology to warrant distinction as a new genus. The description which follows is based on specimens mounted in a hydrous medium and studied under transmitted light.

\section{Systematic Descriptions \\ Triangupapillaesporites gen.nov.}

Type species. Triangupapillaesporites biseratus sp.nov. Diagnosis. Small trilete megaspores approximately circular in outline consisting of three distinctive layers of exine. The individual layers appear to be only firmly attached to each other in the region of the haptotypic structures. A "central body" can be distinguished which consists of a relatively thick layer, approximately circular in outline, and contains within a thin, folded layer, rounded triangular in outline. On either side of sutures on innermost layer of exine, a row of small circular darker coloured areas are clearly defined (thickening of exine (? papillae)). The two layers which form the "central body" appear to be in contact with each other only in region of trilete mark. External to the "central body", the third or outermost layer of exine is relatively thin and, depending on compression direction, may extend beyond equatorial margin of the "central body" in form of a zona. On entire specimens the laesurae are distinct, straight to sinous in outline, varying between greater than half the radius to approximately equal the radius of the "central body" in length. No apical prominence in form of a gula is present, the height of the laesurae being more or less constant between proximal pole and position of the curvaturae.

Remarks. Since this genus is monospecific at the present time, no attempt is made at delineating the variation in ornamentation of the outer layer of exine or variation in size as might be expected in a generic description. The possession of the cushion-like thickenings of the inner layer of the "central body" is considered to be distinctive, together with the three layers of exine. Future work may yield results showing some variation to the type species thus allowing a more broadly encompassing generic description to be made. The most similar genus known from Carboniferous deposits of the northern hemisphere is Triangulatisporites Potonié \& Kremp (1954). Triangulatisporites is similar in that it has three distinct layers of exine, but the outer layer of the exine appears to be more widely attached as indicated by polar and lateral compressions and lacks the distinctive biseriate cushion-like thickenings on the "central body". Winslow $(1959$, p. $38-39$, pl. 10, fig. 9) refers to small papillae on the innermost layers of some specimens of Triangulatisporites triangulatus. However, these thickenings are not arranged in a biseriate form. Winslow (op.cit., p. 36) also refers to ornamentation on the innermost layer of some specimens of Zonalesporites (Ibrahim) Spinner (1965), a much larger "broadly zonate" type of megaspore.

Spinner, in Butterworth \& Spinner (1967), described a new species of megaspore from the same 
geographical area as Triangupapillaesporites and from a close stratigraphical horizon. The species, which lacks the biseriate thickenings on the "central body" (recently confirmed by re-examination of the holotype - see Butterworth \& Spinner, (1967, pl. 4, fig. 2, slide V3/15), was assigned to Triangulatisporites as the most suitable genus available but it was noted that it was atypical of the genus. In the possession of a "central body" with distinctive, localised exinal thickenings (papillae) Triangupapillaesporites most closely compares with the following genera described by Bharadwaj \& Tiwari (1970): Duosporites (Hфeg, Bose \& Manum), Talchirella (Pant \& Srivastava), Gulatitriletes and Surangeaesporites. However, these genera are all based on Gondwanan material and are reported as having only a two layered exine. Only in Duosporites are the thickenings on the "central body" arranged in a form described here as biseriate.

Triangupapillaesporites biseratus sp.nov. (Pl. 1, figs. 1-6)

Derivation of name. After the possession of thickenings of exine in a biseriate form.

Holotype. Pl. 1, fig. 1, slide no. SD/6, stored in the reference collection Micropalaentology Laboratory, Geology Department, University of Sheffield.

\section{Description}

Size and Shape: Small trilete megaspore, approximately circular in outline consisting of a rigid (denser) "central body" surrounded by a relatively thin outer layer of exine which may project beyond the margin of the compressed "central body" in the form of a "zona". The "central body", approximately circular in outline, varies from $450 \mu-800 \mu$ with a mean of $540 \mu$ in maximum diameter (based upon 20 specimens in a hydrous "wet" medium).
Haptotypic structures: The laesurae are distinct, straight to sinous in outline, greater than half the radius of the "central body" in length. The width of the laesurae varies between $20 \mu-25 \mu$ at the base. Although the laesurae vary between $40 \mu-60 \mu$ in height and appear fluted, there is no indication of an apical prominence in the form of a gula. The contact areas are distinct (under reflected light), forming three quarters or more of the proximal surface of the compressed "central body", bounded by curvaturae in the form of ridges which may project $50 \mu$ beyond the margin of the "central body" of oblique compressions. The contact areas are laevigate but on some specimens may appear ornamented in the region of the curvaturae, when viewed by reflected light.

Exine structure and Ornamentation: The exine consists essentially of three layers when viewed with transmitted light. The outer layer is thin and characterised by a combination of small lumina, $10 \mu-20 \mu$ in diameter and positive cone-like elements approximately $2 \mu-5 \mu$ high, which project at the margin. The outer layer projects from the margin of the thicker "central body", in a "zonate form", the amount of projection varies (70$250 \mu \mathrm{m}$ in present study), reflecting the direction of compression and the amount and strength of attachment to the inner "central body". The "central body" is formed by two layers of exine. The outer layer appears laevigate (on corroded specimens) varying from $10-15 \mu \mathrm{m}$ in thickness (as measured in optical sections). The innermost layer is thin, folded, rounded triangular in outline (polar compressions) and appears to be attached to the outer layer in the region of the trilete mark. It is characterised by thickenings or exine, circular in outline and $10-15 \mu \mathrm{m}$ in diameter, arranged in two rows of four or six on either side of the trilete sutures, (i.e. biseriate).

Remarks. T. biseratus closely resembles Duosporites congoensis Hoeg, Bose \& Manum (1955), in the possession of circular thickenings of exine (? papillae)

\section{Explanation of Plate 1}

All figures illustrated by transmitted light, X100 unless stated otherwise. Slides are stored in the reference collection, Micropalaeontology Laboratory, Geology Department, University of Sheffield.

Fig. 1. holotype, slide SD6

Fig. 2, 3. paratypes, slides SD26, SD24

Fig. 4. specimen with outermost layer of exine partly removed, slide SD17

Fig. 5. enlarged (X250) promimal pole area of fig. 6. illustrating the biseriate ? papillae and innermost layer of exine

Fig. 6. denuded specimen illustrating inner "central body", slide SD2 

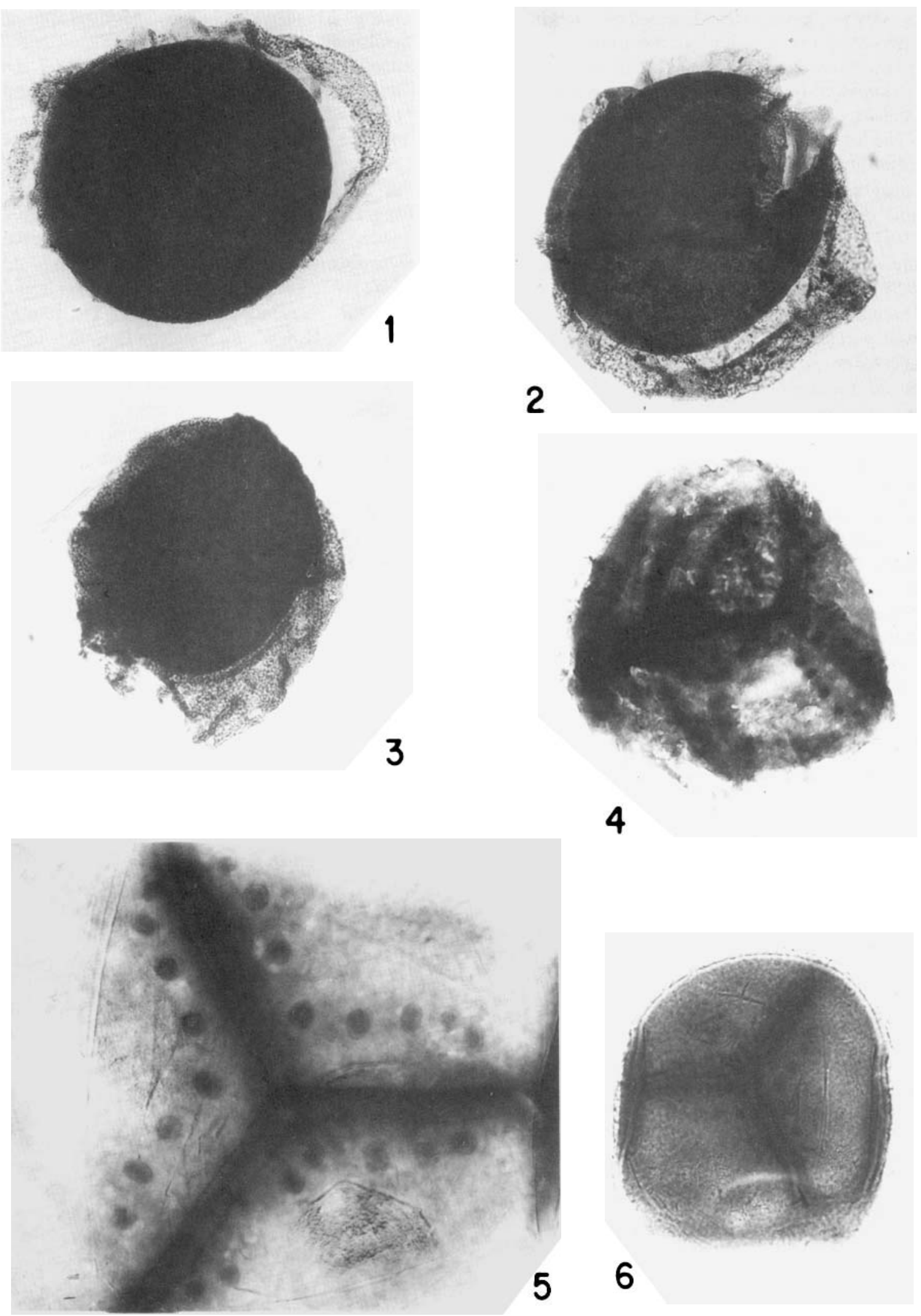
arranged in a biseriate form and in the size of the "central body". However, D.congoensis is reported as having only a two-layered exine. Species of Talchirella (Pant \& Srivastava), Gulatriletes and Surangeaesporites all described by Bharadwaj \& Tiwari (1970) have similar papillate thickenings, but the papillae are not arranged in a biseriate form, and the exine is reported as being of two layers. The above genera and species are also based on Gondwanan material.

$T$. biseratus closely resembles ?Triangulatisporites membranatus described by Spinner in Butterworth \& Spinner (1967). In that publication the present author assigned the species to Triangulatisporites Potonie \& Kremp (1954) as being the most suitable genus available. T. membranatus in Butterworth \& Spinner (op.cit.) closely resembles T.biseratus in overall size, three-layered exine, structure and ornamentation of the outer layer of the exine, but lacks the ? papillate thickenings on the innermost layer of the exine. Because of the similarity of stratigraphical horizons and geographical locality from which the two species have been recorded, the absence of the ? papillae on $T$. membranatus has been confirmed by a recent examination of the holotype and other specimens of the species figured by Spinner in Butterworth \& Spinner (op.cit.). The presence of the ? papillate thickenings on T.biseratus is considered at the present time to be a distinctive morphological character. The question of any variability in the presence of this feature must await further work.

\section{REFERENCES}

Bhardwaj, D.C. \& Tiwari, R.S., 1970. Lower Gondwana Megaspores - A. Monograph. Palaeontographica, 129B, 1-70, pls. 1-15.

Butterworth, M.A. \& Spinner, E., 1967. Lower Carboniferous spores from North-west England.Palaeontology, London, 10, 1-24, pls. 1-5.

Chaloner, W.G., 1959. Devonian megaspores from Arctic Canada. Palaeontology, London, 1, 321-32, pl. 55.

Høeg, O.A., Bose, M.N. \& Manum, S., 1956. On double walls in fossil megaspores, with description of Duosporites congoensis, n.gen., n.sp., Nytt Mag. Bot., Oslo, 4, 101-107, pls. 1-2.

Neves, R., Gueinn, K.J., Clayton, G., Ioannides, N.S., Neville, R.S.W. \& Kruszewska, K., 1973. Palynological Correlations within the Lower Carboniferous of Scotland and Northern England. Trans. R.Soc. Edinb., 69, 2, 23-70, 6 pls., 15 figs., 1 table.

Potonie, R. \& Kremp, G., 1954. Die Gattungen der paläozoischen sporae dispersae und ihre Stratigraphie. Geol. Jb. Hannover, 69, 111-184, pls. 4-20.

Spinner, E., 1965. Westphalian D megaspores from the Forest of Dean Coalfield, England. Palaeontology, London, 8, 82-106, pls. 14-17.

Winslow, M.R., 1959. Upper Mississipian and Pennsylvanian megaspores and other plant micro-fossils from Illinois. Bull. Ill. St. geol. Surv., Urbana, 86, $102 \mathrm{pp} ., 16$ pls. 